\title{
Moderate and deep sedation for non- invasive paediatric procedures in tertiary maternity and children's hospitals in China: a questionnaire survey from China
}

Bo Li', Ruidong Zhang ${ }^{1}$, Yue Huang ${ }^{1}$, Kan Zhang ${ }^{1}$, Chun Yin Wat ${ }^{2}$, Jie Bai ${ }^{1}$, Mazhong Zhang ${ }^{1,3}$ and Jijian Zheng ${ }^{1,3^{*}}$ (D)

\begin{abstract}
Background: Moderate and deep sedation are well-established techniques in many developed countries, and several guidelines have been published. However, they have received attention in China only in recent years. The aim of this study is to investigate current paediatric sedation practices in tertiary children's hospitals and tertiary maternity and children hospitals in China.

Methods: All tertiary children's hospitals and tertiary maternity and children hospitals registered with the National Health Commission of the People's Republic of China were invited to participate in an electronic survey, which included information on the sedation caseload, facility availability, staff structure, clinical skill requirements for sedation providers, fasting guidelines, patient-monitoring practices, and choice of sedatives.

Results: Fifty-eight of the 63 hospitals that completed the survey (92.1\%) provided moderate and deep sedation. Dedicated sedation rooms and post-sedation recovery rooms were found in $14(24.1 \%)$ and 19 (32.8\%) hospitals, respectively. Sedation for non-invasive procedures was primarily performed by anaesthesiologists (69.0\%); however, 75.9\% of the sedation providers had not received paediatric basic or advanced life-support training. Children were asked to fast from clear liquids for at least $2 \mathrm{~h}$ in $44.8 \%$ of hospitals and up to $6 \mathrm{~h}$ in $5.2 \%$ of hospitals; they were asked to fast from solid food/milk for at least $4 \mathrm{~h}$ in $27.6 \%$ of hospitals and more than $8 \mathrm{~h}$ in $1.7 \%$ of hospitals. The most commonly used sedative in all groups was chloral hydrate. For rescue, propofol was the most widely used sedative, particularly for children older than 4 years.
\end{abstract}

Conclusions: Moderate and deep sedation practices vary widely in tertiary children's hospitals and tertiary maternity and children hospitals in China. Optimised practices should be established to improve the quality of moderate and deep sedation.

Keywords: Child, China, Conscious sedation, Deep sedation, Questionnaires, Surveys

\footnotetext{
*Correspondence: zhengjijian626@sina.com

'Department of Anaesthesiology, Shanghai Children's Medical Center, Affiliated with Shanghai Jiao Tong University School of Medicine, National Children's Medical Center, 1678 Dong Fang Road, Shanghai 200127, China ${ }^{3}$ Pediatric Clinical Pharmacology Laboratory, Shanghai Children's Medical Center, National Children's Medical Center, 1678 Dongfang Road, Shanghai, China

Full list of author information is available at the end of the article
}

(c) The Author(s). 2020 Open Access This article is distributed under the terms of the Creative Commons Attribution 4.0 International License (http://creativecommons.org/licenses/by/4.0/), which permits unrestricted use, distribution, and reproduction in any medium, provided you give appropriate credit to the original author(s) and the source, provide a link to the Creative Commons license, and indicate if changes were made. The Creative Commons Public Domain Dedication waiver (http://creativecommons.org/publicdomain/zero/1.0/) applies to the data made available in this article, unless otherwise stated. 


\section{Background}

Moderate and deep sedation techniques play an important role in facilitating paediatric diagnostic procedures such as computed tomography, magnetic resonance imaging, and echocardiography. They assist in diagnostic procedures for uncooperative children and reduce procedure-related stress for cooperative children. In the past 30 years, various guidelines have been published in recognition of the potential risks associated with procedural sedation. In 1985, the American Academy of Pediatrics (AAP) published the first guideline to address safety concerns [1]. Subsequently, the American Society of Anesthesiologists (ASA), the American Academy of Pediatric Dentistry (AAPD), and the American College of Emergency Physicians (ACEP) developed sedation guidelines for different clinical situations [2-4]. These have been updated regularly to enhance the safety and quality of moderate and deep sedation practices in the United States and other developed countries [5-10].

Sedation practices in China are not uniform, possibly due to variability in the workforce, facilities, knowledge, and practice guidelines. There is currently no standardised national practice guideline for procedural sedation in China, and training for sedation providers also varies. Therefore, we aim to investigate current sedation practices in tertiary children's hospitals and tertiary maternity and children hospitals in China, in the hope of contributing to the future establishment of paediatric sedation guidelines in China for moderate and deep sedation.

\section{Methods}

An electronic questionnaire was developed to explore the current moderate and deep sedation practices for non-invasive diagnostic procedures in Chinese tertiary children's hospitals and tertiary maternity and children hospitals. Verbal consent was approved by the Institutional Review Board of Shanghai Children's Medical Centre since our study neither involved the privacy issues of patients nor involved the alterations of paediatric sedation practices (SCMCIRB-W2019018). We identified tertiary children's hospitals and tertiary maternity and children hospitals from a list of facilities registered with the National Health Commission of People's Republic of China. We then contacted the departments of anaesthesiology to determine their willingness to participate in this survey. If sedation was not provided by anaesthesiologists, the person in charge of the sedation service was asked to participate. After oral informed consent was obtained, we created a WeChat Sedation Survey Group using a smartphone and generated the survey questionnaire through the built-in WeChat Mini Program. To avoid multiple replies from the same hospital, only one physician familiar with the sedation service from each hospital was invited to join the WeChat Sedation Survey Group. The questionnaires were released in June 2018, and completed surveys were retrieved by July of the same year. The definitions of light sedation, moderate sedation, and deep sedation were indicated in the questionnaire, and it was made clear that the survey questions did not pertain to light sedation. Light sedation was defined as a drug-induced state during which patients respond normally to verbal commands; although cognitive function and coordination may be impaired, ventilatory and cardiovascular functions are unaffected. The questions in the survey were related to the frequency of moderate- and deep-sedation use, facilities, staff structure, prerequisite skills, fasting practices, monitoring practices, and choice of sedatives.

Statistical analysis was performed using SPSS Version 19.0 (SPSS Inc., College Station, TX, USA). For descriptive analyses, categorical variables were reported as counts and percentages. The variability of data was analysed using a chi-squared test or Fisher's exact test; $p$ values $<0.05$ were considered statistically significant.

\section{Results}

We asked 81 tertiary children's hospitals and tertiary maternity and children hospitals to join the study; 17 did not respond, and 64 agreed to participate. Questionnaires were sent to representatives from each of the 64 hospitals, and valid questionnaires were retrieved from $63(98.4 \%)$ of them. At least one hospital in each province and municipality in China was included, except for the Tibet Autonomous Region and the Ningxia Hui Autonomous Region. According to the National Health Commission of People's Republic of China, there are no tertiary children's hospitals or tertiary maternity and children hospitals registered in these two regions.

\section{Frequency of moderate- and deep-sedation use}

Of the 63 hospitals, 58 (92.1\%) provided moderate and deep sedation for non-invasive paediatric diagnostic procedures. A majority $(N=36,62.1 \%)$ of the hospitals performed moderate-to-deep sedation in fewer than 1000 cases per year. Twelve $(20.7 \%)$ hospitals performed it in 1000-5000 cases per year, and 10 (17.2\%) hospitals performed it in more than 10,000 cases per year. The top 10 centres in terms of number of patients served were located in Shanghai, Chongqing, Guangzhou, Zhengzhou, Xuzhou, Hangzhou, Chengdu, Kunming, Qingdao, and Xining.

\section{Facilities}

Dedicated sedation rooms and post-sedation recovery rooms were reported in only $14(24.1 \%)$ and $19(32.8 \%)$ hospitals, respectively. Of the 10 hospitals with more than 10,000 sedation cases per year, eight (80\%) reported 


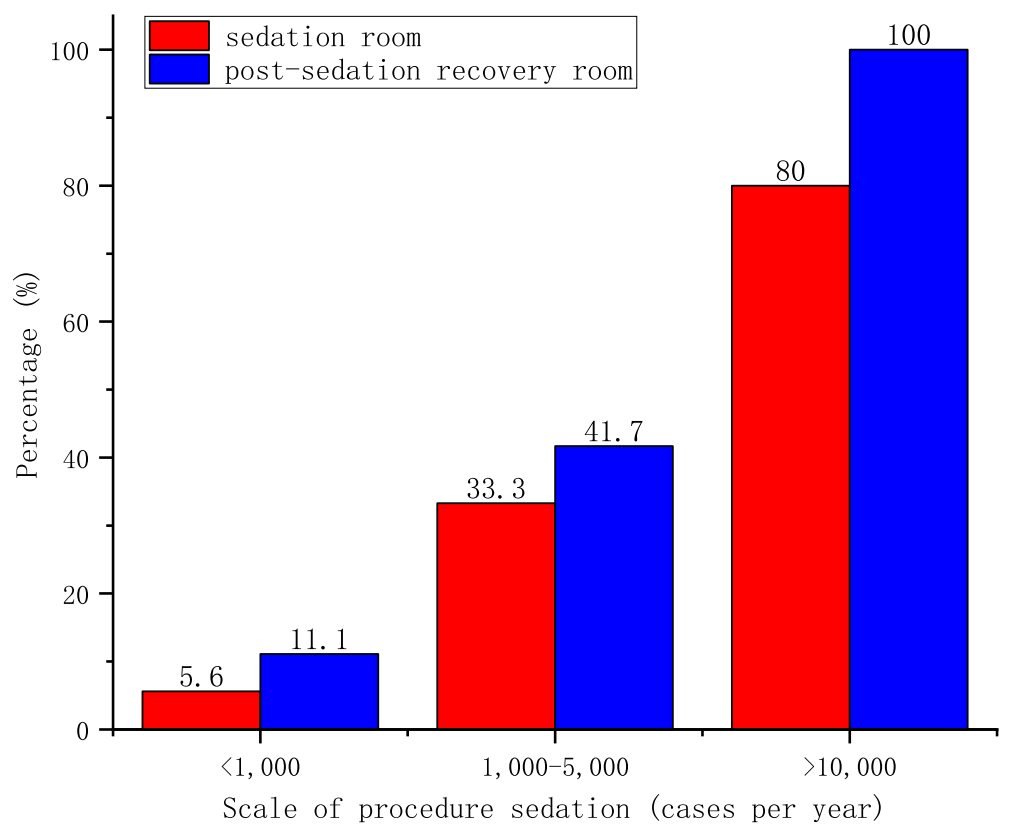

Fig. 1 Scale of the facilities providing moderate and deep sedation in China. Red columns: the percentage of sedation rooms. Blue columns: the percentage of post-sedation recovery rooms

dedicated sedation rooms and all (100\%) reported postsedation recovery rooms. The availability of these rooms was less common in hospitals that managed less than 1000 sedation cases per year $(p<0.001$; Fig. 1$)$.

\section{Staff structure and prerequisite skills}

Anaesthesiologists performed most sedations (69.0\%). Other sedation providers included physicians-in-charge (the first physician to see and care for the patient,
13.8\%), radiologists (6.9\%), and nurses (10.3\%) (Fig. 2). Fifteen (25.9\%) hospitals reported that they employed full-time sedation providers, which, in China, are medical personnel whose only duty is to provide sedation service during that session. Of these 15 hospitals, 13 used anaesthesiologists and two used nurses as full-time sedation providers. Ten of the 14 hospitals with sedation rooms had full-time sedation providers; however, only

\begin{tabular}{|l|l|l|l|l|l|}
\hline Anesthesiologists \\
Physicians-in-charge of the cases \\
Radiologists \\
Nurses
\end{tabular}


Table 1 Ratio of physicians to nurses for moderate and deep sedation in tertiary children's hospitals and tertiary maternity and children hospitals in China

\begin{tabular}{lllllllll}
\hline $\begin{array}{l}\text { Moderate } \\
\text { and deep } \\
\begin{array}{l}\text { sedation } \\
\text { (cases per }\end{array}\end{array}$ & $\begin{array}{l}\text { Hospitals } \\
(n)\end{array}$ & \multicolumn{8}{l}{ Ratio of physicians to nurses } \\
\cline { 3 - 9 } year) & $<1: 1$ & $1: 1$ & $1: 2$ & $1: 3$ & $1: 4$ & $>1: 4$ & Not specified \\
\hline$<1000$ & 36 & 19 & 2 & 0 & 1 & 0 & 2 & 12 \\
$1000-5000$ & 12 & 1 & 2 & 2 & 0 & 2 & 0 & 5 \\
$5000-10,000$ & 0 & $/$ & $/$ & $/$ & $/$ & $/$ & $/$ & $/$ \\
$>10,000$ & 10 & 2 & 0 & 3 & 1 & 2 & 2 & 0 \\
\hline
\end{tabular}

five of the 44 hospitals without sedation rooms had fulltime sedation providers $(p<0.001)$.

The ratio of physicians to nurses is shown in Table 1 . A ratio lower than 1:1 was reported in 19 (52.8\%) hospitals with less than 1000 sedation cases per year and in two $(20.0 \%)$ hospitals with more than 10,000 sedation cases per year. A ratio equal to or more than 1:4 was reported in two (5.6\%) hospitals with less than 1000 sedation cases per year and in four (40\%) hospitals with more than 10,000 sedation cases per year. The ratio was not specified in 12 (33.3\%) hospitals with less than 1000 sedation cases per year, but all hospitals with more than 10,000 sedation cases per year had explicit requirements regarding the ratio of physicians to nurses.

The prerequisite skills for sedation providers are shown in Fig. 2. Ten (17.2\%) hospitals indicated that Paediatric Advanced Life Support (PALS) training is required for staff involved in sedation service, and four (6.9\%) hospitals replied that Paediatric Basic Life Support (PBLS) is required. More than half of the hospitals $(51.7 \%)$ did not specify any training requirements.

\section{Fasting practices}

Solid food or milk was stopped for at least 4, 6, 8, and more than $8 \mathrm{~h}$ before sedation in 27.6, 37.9, 25.9, and $1.7 \%$ of hospitals, respectively. Clear liquids were stopped for at least 2, 4, and $6 \mathrm{~h}$ before sedation in 44.8 , 43.1 , and $5.2 \%$ of hospitals, respectively. Four hospitals (6.9\%) did not report pre-sedation fasting requirements (Table 2).

Table 2 Pre-sedation fasting requirements in China

\begin{tabular}{lll}
\hline Pre-sedation fasting time & Solid food/milk & Clear liquids \\
\hline $2 \mathrm{~h}$ & $/$ & $44.8 \%$ \\
$4 \mathrm{~h}$ & $27.6 \%$ & $43.1 \%$ \\
$6 \mathrm{~h}$ & $37.9 \%$ & $5.2 \%$ \\
$8 \mathrm{~h}$ & $25.9 \%$ & $/$ \\
$>8 \mathrm{~h}$ & $1.7 \%$ & $/$ \\
Not specified & $6.9 \%$ & $6.9 \%$ \\
\hline
\end{tabular}

\section{Monitoring practices}

Pulse oximetry was used in 65.5 and $77.6 \%$ of hospitals during magnetic resonance imaging and non-magnetic procedures, respectively; capnography was used during sedation procedures in approximately $15 \%$ of hospitals (Table 3). Most hospitals monitored pulse oximetry in either a continuous or intermittent manner (Table 4).

\section{Choice of sedatives}

Chloral hydrate was commonly used as the first-line sedative for children. For infants (younger than 1 year), the three most commonly used sedation agents were chloral hydrate (53.4\%), dexmedetomidine $(12.1 \%)$, and diazepam (8.6\%). For older children, chloral hydrate use decreased and dexmedetomidine and propofol use increased. In children older than 4 years of age, the top three sedation agents were chloral hydrate $(24.1 \%)$, propofol (20.7\%), and dexmedetomidine (17.2\%) (Fig. 3).

Rescue sedatives were considered by sedation providers if the patient remained awake $30 \mathrm{~min}$ after the first-choice agent was administered. The term 'remained awake' refers to a Modified Observer's Assessment of Alertness and Sedation Scale score of $\geq 4$ (Table 5). If the first-choice sedative failed, propofol (15.5\%) and inhaled anaesthetics $(15.5 \%)$ were most commonly used in infants, and an additional dose of chloral hydrate was also considered in 7 hospitals (12.1\%). For older children, propofol and dexmedetomidine (instead of inhaled anaesthetics) were popular choices (Fig. 3).

\section{Discussion}

Moderate sedation and deep sedation are wellestablished techniques in many developed countries, and several guidelines have been published. Despite this, these techniques have only recently become prominent in China. Our survey shows that most tertiary children's hospitals and tertiary maternity and children hospitals in China provide moderate and deep sedation for noninvasive procedures. The hospitals that provide sedation on a larger scale tend to have better facilities and staff composition. Pulse oximetry is monitored in more than $65.5 \%$ of hospitals during sedation procedures, but only a few hospitals (about 15\%) perform capnography monitoring. Chloral hydrate is the most commonly chosen sedative agent; however, its use tends to decline and the use of dexmedetomidine and propofol increases gradually with patient age. Propofol (15.5\%) and inhaled anaesthetics $(15.5 \%)$ are the most commonly used rescue sedatives. Our study shows that there are no mandatory training requirements for the staff providing sedation in many hospitals.

Most hospitals in China do not have dedicated sedation rooms or post-sedation recovery rooms. Although it is not specifically mentioned in the guidelines, 
Table 3 Monitoring devices used during moderate and deep sedation in China

\begin{tabular}{lll}
\hline Monitoring devices & Percentage of monitoring events used during sedation \\
\cline { 2 - 3 } & Magnetic procedures & Nonmagnetic procedures \\
\hline Pulse oximetry & $65.5 \%$ & $77.6 \%$ \\
Electrocardiography & $41.4 \%$ & $44.8 \%$ \\
Noninvasive blood pressure & $27.6 \%$ & $34.5 \%$ \\
End-tidal carbon dioxide & $13.8 \%$ & $15.5 \%$ \\
Others & $12.1 \%$ & $5.2 \%$ \\
\hline
\end{tabular}

Notes: The proportions in Table 3 refer to the percentage of hospitals who use the relevant monitoring event during sedation

sedation rooms and post-sedation recovery rooms are necessary so that sedation providers can properly monitor and manage paediatric patients. It is alarming that only 24.1 and $32.8 \%$ of the hospitals that participated in our survey had sedation rooms and post-sedation recovery rooms, respectively. Considering the potential risks of moderate and deep sedation (e.g. vomiting, aspiration, hypotension, and apnoea), we believe that these standard facilities should be available wherever sedation procedures are provided to ensure the safety of paediatric patients.

According to the National Institute for Health and Care Excellence (NICE) guidelines, staff involved in moderate and deep sedation, including physicians and nurses, should have knowledge of and competency in sedation drug pharmacology, assessment of children, monitoring, recovery care, and management of complications [11]. Moderate sedation and deep sedation require teamwork; although there is no specific requirement for the number of team members, all guidelines emphasize that sedation providers must be competent in life-support skills. The NICE guidelines suggest that all providers of moderate and deep sedation should be trained in basic life-support and at least one team member present for the duration of deep sedation should be competent in advanced life-support [11]. The AAP and AAPD also suggest that at least one team member trained in advanced paediatric life support and skilled in airway management and cardiopulmonary resuscitation be present during deep sedation $[6,7]$. It should be noted that although life-support skills are emphasized in all sedation guidelines, no guideline has addressed the question of who should be responsible for sedation. There is no doubt that life-support skills are the specialties of anaesthesiologists; they are also the first choice for sedation management. However, the number of anaesthesiologists is limited and they can hardly fulfil all the needs. Our study reveals that other sedation providers such as nurses and radiologists are also involved. Although accumulating evidences indicate that procedural sedations can be safely and effectively performed in ASA I-II paediatric patients by nonanaesthesiologists, whether this can also be extended to ASA III or higher paediatric patients remains unclear [12-15]. Propofol, a widely used sedative and anaesthetic, has been reported to be safely used for paediatric procedural sedation by non-anaesthesiologists, but whether it can be safely used in paediatric patients with ASA III or higher requires further in-depth investigation $[16,17]$. In addition, modified sedative regimens for paediatric patients, such as a combination of ketamine and propofol, also show a reliable safety profile, indicating that it may be an alternative for nonanaesthesiological sedation providers [18, 19]. Anyway, the constant and immediate availability of anaesthesiological support may continue to be necessary for nonanaesthesiological sedation providers [17].

Sedation providers must be competent in life-support skills. If not, someone with life-support skills must be present for the duration of sedation. In view of this

Table 4 Modes of pulse oximetry monitoring used during moderate and deep sedation in China

\begin{tabular}{lll}
\hline Monitoring modes & Percentage of monitoring modes used during sedation & \\
\cline { 2 - 3 } & Magnetic procedures & Nonmagnetic procedures \\
\hline Continuous & $49.0 \%$ & $53.7 \%$ \\
Intermittent & & $9.2 \%$ \\
$\quad$ every $<5$ min & $8.1 \%$ & $5.6 \%$ \\
every 5-10 min & $10.2 \%$ & $3.7 \%$ \\
every $10-15$ min & $/$ & $1.9 \%$ \\
$\quad$ every $>15$ min & $/$ & $25.9 \%$ \\
Not specified & $32.7 \%$ & \\
\hline
\end{tabular}




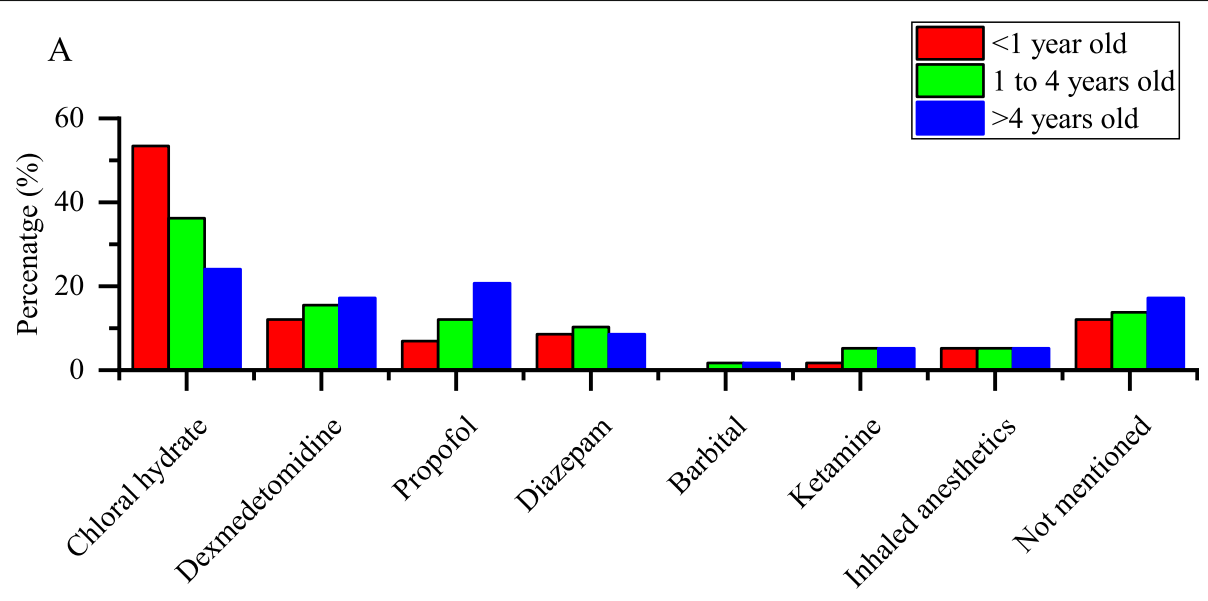

B

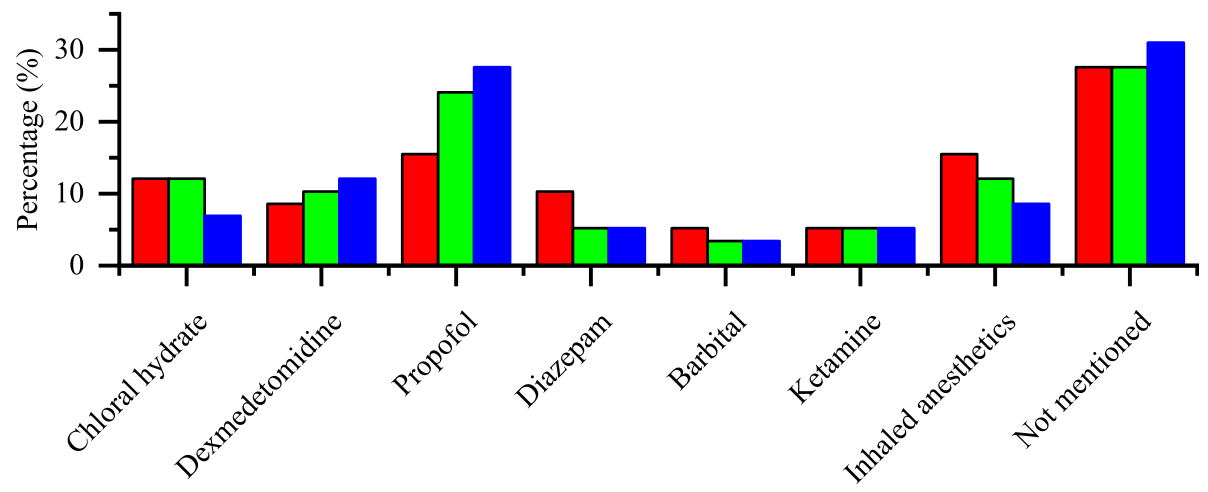

A: First-choice sedatives B: Choice of rescue sedatives

Fig. 3 Choice of sedatives for children of different ages in China. a: the usage rate of various sedatives as first-choice sedatives in children of different ages. $\mathbf{b}$ : the usage rate of various sedatives as rescue sedatives in children of different ages. Red columns: children under 1 year old. Green columns: children 1 to 4 years old. Blue columns: children over 4 years old

point, we think that instead of asking "Who should manage sedation?" we should ask, "What training should sedation providers receive?" According to the guidelines mentioned above, training should include sedation drug pharmacology, assessment of children, monitoring

Table 5 Modified Observer's Assessment of Alertness and Sedation Scale (MOAA/S)

\begin{tabular}{ll}
\hline Score & Items \\
\hline 0 & Dose not respond to a noxious stimulus \\
1 & Dose not respond to mild prodding or shaking \\
2 & Respond only after mild prodding or shaking \\
3 & Respond only after name is called loudly and repeatedly \\
4 & Lethargic respond to name spoken in normal tone \\
5 & Appears asleep but responds readily to name spoken in \\
6 & normal tone \\
& sppears alert and awake and responds readily to name \\
\hline
\end{tabular}

procedures, recovery care, and management of complications. Life-support courses should also be included. PBLS or PALS certification is certainly advantageous; however, it does not mean a provider has been trained to manage sedation. At present, there is no standard training course for sedation providers in China. Specific credentialing and training strategies should be considered in the development of a national guideline. Effective sedation education and training, especially for nonanaesthesiologists, is essential to improve patient safety during moderate and deep sedation. High-fidelity simulation might be an ideal solution; it has been shown to improve skills, knowledge, self-confidence, awareness of emergency, crisis resource management, and teamwork. However, as far as we know, minimal content has been developed for sedation training. Moreover, high-fidelity simulation is costly and requires expertise for the operation of the equipment, which has restricted its popularization. 
The NICE guidelines suggest that fasting is not needed for moderate sedation, during which the child maintains verbal contact with the sedation provider. For children who cannot maintain verbal contact (i.e. moderate-todeep sedation) the 2-4-6 fasting rule should apply [11]. However, it is difficult to accurately control the depth of sedation in clinical practice due to differences in pharmacodynamics and pharmacokinetics. The necessity of pre-sedation fasting has been debated. Many published studies have reported no association between fasting duration and adverse events such as vomiting and pulmonary aspiration [20-22]. Furthermore, the risk of hypovolemia and hypoglycaemia caused by prolonged fasting cannot be ignored in critically ill children; in these cases, a shorter fasting time should be considered. In our institution, milk is allowed $2 \mathrm{~h}$ before procedural sedation for children with congenital heart disease. Adverse events such as vomiting and aspiration are extremely rare. It is necessary to have more experienced staff and rescue equipment available to ensure the safety of these children, but we believe that the risks are controllable.

Insufficient monitoring is another problem of moderate and deep sedation in China. Pulse oximetry, electrocardiography, non-invasive blood pressure, and end-tidal carbon dioxide monitoring during moderate and deep sedation is performed in $65.5,41.4,27.6$, and $13.8 \%$ of hospitals during magnetic procedures, respectively, and in $77.6,44.8,34.5$, and $15.5 \%$ of hospitals during nonmagnetic procedures, respectively. This reveals that these monitoring procedures are adopted less frequently than previously reported [23]. End-tidal carbon dioxide monitoring is believed to be more sensitive than pulse oximetry for respiratory events, which can lead to hypoxemia during procedures $[24,25]$; the latest ASA guidelines also state that continuous monitoring of ventilatory function with capnography should supplement standard monitoring [9].

The choice of sedatives is another interesting topic. Chloral hydrate was the most commonly used firstchoice sedative in our study because of its relatively benign clinical profile and low cost. Other sedatives intended for general anaesthesia (propofol and ketamine) and even inhaled anaesthetics are the first choice in some hospitals. However, 10 years ago, chloral hydrate may have been one of the only options in China (another option may have been barbiturates) for paediatric moderate and deep sedation. There are two reasons for this. First, anaesthesiologists have only recently gradually taken over paediatric moderate and deep sedation practice in China. Sedatives intended for general anaesthesia and inhaled anaesthetics are not considered alternatives if anaesthesiologists are not present. Second, at that time, dexmedetomidine was not yet approved for paediatric clinical use in China, whereas it is now widely used as an ideal sedative. It can be easily administrated intranasally, and children tolerate it well. Miller et al. reported that 2 and $3 \mu \mathrm{g} \cdot \mathrm{kg}^{-1}$ of intranasal dexmedetomidine were as effective for transthoracic echocardiography sedation as oral chloral hydrate, with similar sedation onset and recovery times in infants and toddlers [26]. Dexmedetomidine can also be used as a rescue sedative. After failed chloral hydrate sedation, the rescue success rate of dexmedetomidine increases in a dose-dependent manner [27], and the effective dose 50 of dexmedetomidine for rescue increases with age in those younger than 3 years [28]. Compared with chloral hydrate, intranasal dexmedetomidine has a higher rescue success rate than a second dose of chloral hydrate after failed chloral hydrate sedation [29]. It should be noted that all references cited in this paragraph are the results of clinical trials for Chinese children. We believe that dexmedetomidine will be more popular as a safe, effective, and well-tolerated sedative in China in the future.

Ketamine is another widely used sedation agent; it can be used safely and effectively for paediatric procedural sedation [30], especially for invasive procedures, because of its analgesic properties [31-33]. Recent studies have reported that ketamine can be used in combination with other sedatives for better sedation quality and fewer adverse events [34-36]. Ketamine seems to be an ideal sedative in most cases; however, only a few providers reported using ketamine as a sedative in our study, probably because it is strictly regulated and difficult to acquire in China.

\section{Limitations}

Although all tertiary children's hospitals and tertiary maternity and children hospitals registered with the $\mathrm{Na}$ tional Health Commission of the People's Republic of China were asked to participate, 17 hospitals could not be contacted. Some limitations also exist in the study design; only one physician from each hospital was invited to join the survey. Prescribing habits may vary among physicians, other providers (e.g. emergency department doctors) may be involved, and even fasting and monitoring practices may not be strictly enforced after hours. Therefore, responses from one physician may not accurately represent all providers within the institution. Additionally, procedural sedation practices outside of the hospital setting were not captured in our study. All the limitations mentioned above could results in bias. However, the hospitals included in our study did represent the tertiary centres providing paediatric service in different provinces across China, and we believe that the study still sheds light on the state of sedation practice in China. 


\section{Conclusions}

Moderate and deep sedation practices, including facilities, staff structure, prerequisite skills, fasting practices, monitoring practices, and choice of sedatives, vary widely among the tertiary children's hospitals and tertiary maternity and children hospitals in China. Sedation providers in China should work together to established and promulgate evidence-based sedation standards to improve the quality of sedation service in the country.

\section{Supplementary information}

Supplementary information accompanies this paper at https://doi.org/10. 1186/s12913-019-4885-4

Additional file 1: Questionnaire. Description of data: the questionnaire used in our study.

\section{Abbreviations}

AAP: American Academy of Pediatrics; AAPD: American Academy of Pediatric Dentistry; ACEP: American College of Emergency Physicians; ASA: American Society of Anesthesiologists; NICE: National Institute for Health and Care Excellence; PALS: Paediatric Advanced Life Support; PBLS: Paediatric Basic Life Support

\section{Acknowledgements}

Not applicable.

\section{Availability of data and materia}

We have included the questionnaire used in this study as Additional file 1. The datasets used and analysed during the current study are available from the corresponding author upon request.

\section{Authors' contributions}

$\mathrm{BL}$ was a major contributor in writing the manuscript. RZ, YH, and CYW were responsible for contacting the hospitals. $K Z$ analysed and interpreted the data. The questionnaire was designed by $B L, J B, M Z$, and JZ. All authors read and approved the submitted version of the manuscript.

\section{Funding}

This study was supported by the Pudong New District Science and Technology Development Innovation Foundation (PKJ2016-Y34). The funder had no role in the design, data collection, analysis, interpretation, or writing of the manuscript.

\section{Ethics approval and consent to participate}

Verbal consent was approved by the Institutional Review Board of Shanghai Children's Medical Centre since our study neither involved the privacy issues of patients nor involved the alterations of paediatric sedation practices (SCMCIRB-W2019018).

\section{Consent for publication}

Not applicable.

\section{Competing interests}

The authors have no conflicts of interest to declare.

\section{Author details}

'Department of Anaesthesiology, Shanghai Children's Medical Center, Affiliated with Shanghai Jiao Tong University School of Medicine, National Children's Medical Center, 1678 Dong Fang Road, Shanghai 200127, China. 2Department of Anaesthesiology and Perioperative Medicine, Hong Kong Children's Hospital, 1 Shing Cheong Road, Kowloon, Hong Kong. ${ }^{3}$ Pediatric Clinical Pharmacology Laboratory, Shanghai Children's Medical Center, National Children's Medical Center, 1678 Dongfang Road, Shanghai, China.
Received: 27 June 2019 Accepted: 30 December 2019

Published online: 08 January 2020

\section{References}

1. American Academy of Pediatrics Committee on Drugs. Guidelines for the elective use of conscious sedation, deep sedation, and general anesthesia in pediatric patients. Pediatr. 1985;76:317-21.

2. American Society of Anesthesiologists Task Force on Sedation and Analgesia by Non-Anesthesiologists. Practice guidelines for sedation and analgesia by non-anesthesiologists. Anesthesiol. 1996;84:459-71.

3. Coté CJ, Wilson S. American Academy of Pediatrics, American Academy of pediatric dentistry, work group on sedation. Guidelines for monitoring and management of pediatric patients during and after sedation for diagnostic and therapeutic procedures: an update. Pediatr. 2006;118:2587-602.

4. Jagoda AS, Campbell M, Karas S Jr, Mariani PJ, Shepherd SM, Cantrill SV, et al. Clinical policy for procedural sedation and analgesia in the emergency department. Ann Emerg Med. 1998;31:663-77.

5. Coté CJ, Wilson S. American Academy of Pediatrics, American Academy of pediatric dentistry, work group on sedation. Guidelines for monitoring and management of pediatric patients during and after sedation for diagnostic and therapeutic procedures: an update. Paediatr Anaesth. 2008;18:9-10.

6. Cote CJ, Wilson S. Guidelines for monitoring and management of pediatric patients before, during, and after sedation for diagnostic and therapeutic procedures: update 2016. Pediatr. 2016;138:e20161212.

7. American Academy of Pediatric Dentistry. Guideline on use of anesthesia personnel in the administration of office-based deep sedation/general anesthesia to the pediatric dental patient. Pediatr Dent. 2016;38:246-9.

8. American Society of Anesthesiologists Task Force on Sedation and Analgesia by Non-Anesthesiologists. Practice guidelines for sedation and analgesia by non-anesthesiologists. Anesthesiol. 2002;96:1004-17.

9. Practice guidelines for moderate procedural sedation and analgesia 2018: a report by the American Society of Anesthesiologists Task Force on Moderate Procedural Sedation and Analgesia, the American Association of Oral and Maxillofacial Surgeons, American College of Radiology, American Dental Association, American Society of Dentist Anesthesiologists, and Society of Interventional Radiology. Anesthesiol. 2018;128:437-79. https:// anesthesiology.pubs.asahq.org/article.aspx?articleid=2670190.

10. Godwin SA, Burton JH, Gerardo CJ, Hatten BW, Mace SE, Silvers SM, et al. Clinical policy: procedural sedation and analgesia in the emergency department. Ann Emerg Med. 2014;63:247-58 e18.

11. NICE. Published guidance and advice | Guidance | NICE. 2010. Available from: https://www.nice.org.uk/guidance/cg112.

12. Sury MR, Hatch DJ, Deeley T, Dicks-Mireaux C, Chong WK. Development of a nurse-led sedation service for paediatric magnetic resonance imaging. Lancet. 1999;353:1667-71.

13. Barbi E, Gerarduzzi T, Marchetti F, Neri E, Verucci E, Bruno I, et al. Ventura a: deep sedation with propofol by nonanesthesiologists: a prospective pediatric experience. Arch Pediatr Adolesc Med. 2003;157:1097-103.

14. Kamat PP, McCracken CE, Gillespie SE, Fortenberry JD, Stockwell JA, Cravero $J P$, et al. Pediatric critical care physician-administered procedural sedation using propofol: a report from the pediatric sedation research consortium database. Pediatr Crit Care Med. 2015;16:11-20.

15. Mason KP, Padua H, Fontaine PJ, Zurakowski D. Radiologist-supervised ketamine sedation for solid organ biopsies in children and adolescents. AJR Am J Roentgenol. 2009:192:1261-5.

16. Chiaretti A, Benini F, Pierri F, Vecchiato K, Ronfani L, Agosto C, et al. Safety and efficacy of propofol administered by paediatricians during procedural sedation in children. Acta Paediatr. 2014;103:182-7.

17. Barbi E, Petaros P, Badina L, Pahor T, Giuseppin I, Biasotto E, et al. Deep sedation with propofol for upper gastrointestinal endoscopy in children, administered by specially trained pediatricians: a prospective case series with emphasis on side effects. Endoscopy. 2006;38:368-75.

18. Grunwell JR, Travers C, Stormorken AG, Scherrer PD, Chumpitazi CE, Stockwell JA, et al. Pediatric procedural sedation using the combination of ketamine and propofol outside of the emergency department: a report from the pediatric sedation research consortium. Pediatr Crit Care Med. 2017;18:e356-63.

19. Chiaretti A, Ruggiero A, Barbi E, Pierri F, Maurizi P, Fantacci C, et al. Comparison of propofol versus propofol-ketamine combination in pediatric oncologic procedures performed by non-anesthesiologists. Pediatr Blood Cancer. 2011;15(57):1163-7. 
20. Thorpe RJ, Benger J. Pre-procedural fasting in emergency sedation. Emerg Med J. 2010;27:254-61.

21. Clark M, Birisci E, Anderson JE, Anliker CM, Bryant MA, Downs C, et al. The risk of shorter fasting time for pediatric deep sedation. Anesth Essays Res. 2016;10:607-12.

22. Bhatt M, Johnson DW, Taljaard M, Chan J, Barrowman N, Farion K, et al. Association of preprocedural fasting with outcomes of emergency department sedation in children. JAMA Pediatr. 2018;172:678-85.

23. Langhan ML, Mallory M, Hertzog J, Lowrie L, Cravero J. Pediatric sedation research consortium. Physiologic monitoring practices during pediatric procedural sedation: a report from the pediatric sedation research consortium. Arch Pediatr Adolesc Med. 2012;166:990-8.

24. Beitz A, Riphaus A, Meining A, Kronshage T, Geist CM, Wagenpfeil S, et al. Capnographic monitoring reduces the incidence of arterial oxygen desaturation and hypoxemia during propofol sedation for colonoscopy: a randomized, controlled study (ColoCap study). Am J Gastroenterol. 2012; 107:1205-12.

25. Langhan ML, Shabanova V, Li FY, Bernstein SL, Shapiro ED. A randomized controlled trial of capnography during sedation in a pediatric emergency setting. Am J Emerg Med. 2015;33:25-30.

26. Miller J, Xue B, Hossain M, Zhang MZ, Loepke A, Kurth D. Comparison of dexmedetomidine and chloral hydrate sedation for transthoracic echocardiography in infants and toddlers: a randomized clinical trial. Paediatr Anaesth. 2016;26:266-72

27. Li BL, Yuen VM, Song XR, Ye J, Ni J, Huang JX, et al. Intranasal dexmedetomidine following failed chloral hydrate sedation in children. Anaesth. 2014;69:240-4.

28. Zhang W, Fan Y, Zhao T, Chen J, Zhang G, Song X. Median effective dose of intranasal dexmedetomidine for rescue sedation in pediatric patients undergoing magnetic resonance imaging. Anesthesiol. 2016;125:1130-5.

29. Zhang W, Wang Z, Song X, Fan Y, Tian H, Li B. Comparison of rescue techniques for failed chloral hydrate sedation for magnetic resonance imaging scans - additional chloral hydrate vs. intranasal dexmedetomidine. Paediatr Anaesth. 2016;26:273-9.

30. Grunwell JR, Travers C, McCracken CE, Scherrer PD, Stormorken AG, Chumpitazi $C E$, et al. Procedural sedation outside of the operating room using ketamine in 22,645 children: a report from the pediatric sedation research consortium. Pediatr Crit Care Med. 2016;17:1109-16.

31. Yee R, Chay PL, Tham LP. Safety and effectiveness of intramuscular ketamine sedation in the management of children with oro-dental trauma in a paediatric emergency department. Dent Traumatol. 2019;4. [Epub ahead of print]. https://onlinelibrary.wiley.com/doi/abs/10.1111/edt.12497.

32. Wiik AV, Patel P, Bovis J, Cowper A, Pastides PS, Hulme A, et al. Use of ketamine sedation for the management of displaced paediatric forearm fractures. World J Orthop. 2018;9:50-7.

33. Oh S, Kingsley K. Efficacy of ketamine in pediatric sedation dentistry: a systematic review. Compend Contin Educ Dent. 2018;39:e1-4.

34. Hu Y, Xu W, Cao F. A meta-analysis of randomized controlled trials: combination of ketamine and propofol versus ketamine alone for procedural sedation and analgesia in children. Intern Emerg Med. 2019;14: 1159-65.

35. Schmitz A, Weiss M, Kellenberger C, O'Gorman Tuura R, Klaghofer R, Scheer I, et al. Sedation for magnetic resonance imaging using propofol with or without ketamine at induction in pediatrics - a prospective randomized double-blinded study. Paediatr Anaesth. 2018;28:264-74.

36. Abulebda K, Patel VJ, Ahmed SS, Tori AJ, Lutfi R, Abu-Sultaneh S. Comparison between chloral hydrate and propofol-ketamine as sedation regimens for pediatric auditory brainstem response testing. Braz $J$ Otorhinolaryngol. 2019;85:32-6.

\section{Publisher's Note}

Springer Nature remains neutral with regard to jurisdictional claims in published maps and institutional affiliations.

Ready to submit your research? Choose BMC and benefit from:

- fast, convenient online submission

- thorough peer review by experienced researchers in your field

- rapid publication on acceptance

- support for research data, including large and complex data types

- gold Open Access which fosters wider collaboration and increased citations

- maximum visibility for your research: over $100 \mathrm{M}$ website views per year

At BMC, research is always in progress.

Learn more biomedcentral.com/submissions 